\title{
Selective Estrogen Receptor Modulators: A Potential Option For Non-Binary Gender-Affirming Hormonal Care?
}

\section{OPEN ACCESS}

Edited by:

Rosa Fernández,

University of A Coruña CICA-INIBIC

Strategic Group, Spain

Reviewed by:

Mireia Mora Porta

Hospital Clínic de Barcelona, Spain Irene Halperin Rabinovich,

Hospital Clínic, Spain

*Correspondence:

Ken C. Pang

ken.pang@mcri.edu.au

Specialty section:

This article was submitted to Neuroendocrine Science,

a section of the journal

Frontiers in Endocrinology

Received: 27 April 2021 Accepted: 02 June 2021

Published: 18 June 2021

Citation:

Xu JY, O’Connell MA, Notini L, Cheung AS, Zwickl S and Pang KC (2021) Selective Estrogen Receptor

Modulators: A Potential Option For Non-Binary Gender-

Affirming Hormonal Care?

Front. Endocrinol. 12:701364. doi: 10.3389/fendo.2021.701364

\begin{abstract}
Jane Y. Xu ${ }^{1}$, Michele A. O'Connell ${ }^{2,3,4}$, Lauren Notini ${ }^{2,5}$, Ada S. Cheung ${ }^{6}$, Sav Zwickl ${ }^{6}$ and Ken C. Pang $2,3,4 *$

${ }^{1}$ Geisel School of Medicine, Dartmouth College, Hanover, NH, United States, ${ }^{2}$ Clinical Sciences and Genetics Themes, Murdoch Children's Research Institute, Parkville, VIC, Australia, ${ }^{3}$ Department of Adolescent Medicine, Royal Children's Hospital, Melbourne, VIC, Australia, ${ }^{4}$ Department of Paediatrics, University of Melbourne, Parkville, VIC, Australia, ${ }^{5}$ Melbourne Law School, University of Melbourne, Parkville, VIC, Australia, ${ }^{6}$ Trans Health Research Group, Department of Medicine (Austin Health), University of Melbourne, Heidelberg, VIC, Australia
\end{abstract}

Gender dysphoria describes the distress associated with having a gender identity that differs from one's birth-assigned sex. To relieve this distress, transgender, and gender diverse (henceforth, trans) individuals commonly undergo medical transition involving hormonal treatments. Current hormonal treatment guidelines cater almost exclusively for those who wish to transition from male to female or vice versa. In contrast, there is a dearth of hormonal options for those trans individuals who identify as non-binary and seek an androgynous appearance that is neither overtly male nor female. Though prolonged puberty suppression with gonadotrophin releasing hormone agonists ( $\mathrm{GnRHa}$ ) could in theory be gender-affirming by preventing the development of unwanted secondary sex characteristics, this treatment option would be limited to pre- or peri-pubertal adolescents and likely have harmful effects. Here, we discuss the theoretical use of Selective Estrogen Receptor Modulators (SERMs) for non-binary people assigned male at birth (AMAB) who are seeking an androgynous appearance through partial feminization without breast growth. Given their unique range of pharmacodynamic effects, SERMs may represent a potential gender-affirming treatment for this population, but there is a lack of knowledge regarding their use and potentially adverse effects in this context.

Keywords: transgender, gender non-binary, gender dysphoria, hormone replacement therapy, selective estrogen receptor modulators

\section{INTRODUCTION}

Trans individuals have a gender identity that is different from the sex they were assigned at birth, as opposed to cisgender people, whose gender identity corresponds with their assigned sex (1). Although some trans individuals identify as either male or female, others have a non-binary gender identity that does not accord with either of these traditional options. Whilst non-binary is a gender

Abbreviations: $A F A B$, assigned female at birth; AMAB, assigned male at birth; GnRHa, gonadotrophin releasing hormone agonists; SERM, selective estrogen receptor modulator. 
identity in itself, it is also an umbrella term that encompasses any gender identity that is not exclusively male or female and may include people who identify as genderfluid, gender nonconforming, transmasculine, transfeminine or agender amongst others. Non-binary individuals in recent studies constitute more than $25 \%$ of the trans population (1-3).

Like trans people with binary identities, those with a nonbinary gender identity frequently face social difficulties, including social exclusion at school/work and feelings of isolation. As a result, these individuals often experience poor mental health that is worse than those with binary identities (1, 4). In studies using self-report surveys, non-binary people were less likely to have family support, while significantly more likely to feel isolated, report poorer mental health, and consider suicide than trans people with binary identities $(1,2,4,5)$. Moreover, non-binary individuals frequently encounter a lack of understanding within society regarding their gender identity, including from health professionals (6).

A common reason for poor mental health in trans (including non-binary) individuals is gender dysphoria (GD), which is the distress associated with having a gender identity that differs from one's sex assigned at birth (7). Non-binary people seeking assistance to reduce their GD now constitute a significant proportion (10-30\%) of referrals to paediatric and adult gender clinics $(1,8)$. Given the growing population of non-binary individuals seeking gender-affirming clinical care and the highly vulnerable nature of this population (9), it is important to have appropriate medical options to help them achieve a body they regard as consistent with their identity and to reduce their GD.

Medical treatment with gender-affirming hormones, such as testosterone and estradiol may be appropriate for some nonbinary individuals who wish to masculinize or feminize respectively $(10,11)$. However, other non-binary individuals may seek an androgynous body that is neither overtly male nor female, and there is a lack of medical treatment options specifically tested or approved for use in this group to prevent the development of secondary sex characteristics on an ongoing basis (12). In this article, we therefore consider Selective Estrogen Receptor Modulators (SERMs) as a potential treatment option for non-binary people assigned male at birth (AMAB) who wish to partially feminize without undergoing breast development.

\section{CURRENT TREATMENT OPTIONS FOR NON-BINARY TRANS PEOPLE}

Currently, medical transition options for trans people vary depending on an individual's pubertal stage. For trans adults, treatment options to induce secondary sex characteristics consistent with a person's gender identity include genderaffirming hormone therapy and surgical interventions $(10,11)$. Gender-affirming hormone therapy may involve testosterone for trans people assigned female at birth (AFAB) and estradiol and anti-androgens for trans people $\mathrm{AMAB}(10,11)$. For trans adolescents in early/mid puberty, gonadotropin-releasing hormone agonists (GnRHa), commonly known as "puberty blockers", may be given to suppress puberty before or in conjunction with the use of gender-affirming hormone treatment $(10,11,13,14)$. The effects of GnRHa are considered reversible insofar as stopping treatment allows puberty to resume $(10,11,13,14)$. While many effects of testosterone and estradiol are reversible, some including voice deepening and breast development are not $(10,13)$. The availability of irreversible surgical interventions for adolescents depends on the age and needs of the individual. Individuals in some jurisdictions are able to access chest reconstructive surgery but rarely genital surgery before the age of 18 years (13).

Under current treatment schema, non-binary people who wish for an androgynous body have limited treatment options. For those AFAB, low-dose testosterone is being used empirically with the aim of reducing feminine features by helping to re-distribute adipose tissue and deepen the voice (12). Such effects may be difficult to selectively titrate while avoiding other potentially unwanted masculinizing changes such as facial hair growth. In addition, chest dysphoria is regularly experienced by trans individuals $\mathrm{AFAB}$, and chest reconstructive surgery can enable removal of unwanted breast tissue for those who have progressed through puberty (13). Those AMAB may choose to use low-dose estradiol to partially feminize, though the widespread effects of estradiol could potentially cause unwanted feminising changes, such as breast growth (12). For non-binary adolescents who present in early puberty, long-term GnRHa use may provide a theoretical solution to maintain an androgynous appearance without any secondary sex characteristics (15). However, such a strategy carries substantial risks as described below, which limits its use for this purpose.

\section{MAINTAINING ANDROGYNY VIA LONG- TERM PUBERTY SUPPRESSION}

Pubertal suppression with GnRHa blocks the release of luteinizing hormone (LH) and follicle-stimulating hormone (FSH) from the pituitary gland, preventing production of testosterone and estradiol from the testes and ovaries respectively (16). Without testosterone or estradiol, sex-specific secondary sex characteristics, such as breast development in those $\mathrm{AFAB}$ or voice deepening in those $\mathrm{AMAB}$, do not progress (16). In this way, for many trans adolescents, puberty blockers can help prevent an exacerbation of GD and the attendant anxiety that often accompanies typical progression through puberty (17).

However, since the pubertal increase in either testosterone or estradiol levels is important for the development and function of other body systems, use of GnRHa in trans adolescents can also cause unwanted outcomes. For example, pubertal sex hormone is essential for healthy bone development, with testosterone and estradiol acting as key promoters of new bone deposition and increased bone mass (18). Consistent with this, use of GnRHa in trans adolescents is associated with reduced bone mineral density (BMD) $(19,20)$, and the potential functional impact of this on 
bone quality and fracture risk in adulthood remains unknown (21). Long-term GnRHa therapy from early puberty would also be expected to inhibit typical pubertal development of reproductive potential $(15,22)$; this effect is considered likely reversible but has not been directly studied (22). Finally, significant brain and cognitive development occurs during adolescence. Although it is unclear to what extent pubertal hormones positively influence this development, it stands to reason that puberty suppression might impact this process (16, 17, 21).

For trans adolescents who receive puberty blockers and wish to subsequently feminize or masculinize their bodies, use of gender-affirming hormones is likely to ameliorate some of these concerns associated with GnRHa use, though further study is required $(14,23)$. However, for non-binary adolescents who wish to undertake long-term puberty suppression to maintain an androgynous body, these risks will presumably be exacerbated. Although such an approach might be ethically justified in some circumstances $(15,24)$, most physicians would be unlikely to prescribe puberty blockers as independent, long-term treatment (25). In addition, this treatment would not be effective for nonbinary individuals who have completed puberty. Having alternative therapeutic options in such cases would therefore be valuable.

\section{SERMS: A POSSIBLE SOLUTION?}

\section{Overview}

SERMs are chemically diverse compounds that bind to alpha or beta subunits of the estrogen receptor and produce both agonistic (i.e., estrogenic) and antagonistic (i.e., antiestrogenic) effects within different cell types and tissues (Table 1) $(23,43)$. With the advent of newer drug designs in recent decades, SERMs are categorized into three generations. In general, each generation has estrogenic and anti-estrogenic effects on different parts of the body. In reality, many effects are drug-specific, still debated, or unknown (23). Across the first, second and third generations of SERMs, the most popular approved treatments are tamoxifen, raloxifene (RLX), and lasofoxifene respectively (29). Tamoxifen is most commonly used to treat pre-menopausal breast cancer (23). RLX is widely approved for post-menopausal osteoporosis (35). Lasofoxifene has been approved in the EU for both osteoporosis and vaginal atrophy (45) and is currently being reviewed by the FDA as a treatment for breast cancer (48).

\section{Theoretical Use of SERMs as a Treatment for Non-Binary Individuals AMAB}

Given their tissue-specific antagonistic and agonistic effects, SERMs could potentially be suitable either as an independent or combined treatment modality for the gender-affirming care of non-binary individuals $\mathrm{AMAB}$ who desire partial feminization without breast growth. Specific SERMs (Table 1) have been shown to inhibit breast and endometrial tissue growth, while exhibiting beneficial estrogenic effects on bones in pre- and postmenopausal cisgender women $(35,43)$. These effects are not wellstudied in people AMAB. Theoretically, a SERM with antiestrogenic effects on breast but estrogenic effects on bone, fat composition, and skin might offer appeal as a hormone treatment for a non-binary person $\mathrm{AMAB}$ who desires an androgynous body.

While SERMs could be used independently for non-binary adults $A M A B$ to induce partial feminization, SERMs alone would not be expected to block unwanted pubertal masculinization in non-binary adolescents AMAB. Androgen blockade would still be required in this younger population. In the following sections, we explore the theoretical use of SERMs in this context, extrapolating from what is known about their use in other situations.

\section{SERMs May Promote Feminine Body Shape and Changes in Skin}

Similar to estradiol hormone treatment, SERMs have been found to promote changes in body composition and skin that may be desired by non-binary people AMAB. In post-menopausal cisgender women, studies have found RLX to be an estrogen receptor agonist in adipose tissue, promoting shifts from android to gynoid fat patterns (40) and increasing fat-free mass and total body water (41). In this way, RLX may contribute to a more feminine body shape. In other studies of post-menopausal cisgender women, RLX has been shown to increase skin elasticity (31) and stimulate collagen biosynthesis (32). Thus, RLX is likely to promote softer, more stereotypically feminine

TABLE 1 | Differential effects of GnRHa, SERMs, and Estrogen.

\begin{tabular}{|c|c|c|c|c|c|c|}
\hline Treatment Type & Breast Tissue & Vertebral Bones & Non-Vertebral Bones & $\begin{array}{l}\text { Body Composition/Gynoid } \\
\text { Fat Distribution }\end{array}$ & Skin & DVT Risk \\
\hline GnRHa & $-(13,21)$ & $-(19-21)$ & $-(19-21)$ & $\operatorname{MR}(21,26)$ & UN & $+(27)$ \\
\hline Estradiol & $+++(28)$ & $+++(28,29)$ & $+++(28,29)$ & $+(30)$ & $++(31-33)$ & $+(28,34)$ \\
\hline $\begin{array}{l}\text { Tamoxifen } \\
\text { (SERM Gen 1) }\end{array}$ & $-(29,35)$ & $+(29)$ & $+(35,36)$ & UN & $-(33)$ & $++(29,35,37)$ \\
\hline $\begin{array}{l}\text { Raloxifene } \\
\text { (SERM Gen 2) }\end{array}$ & $-(29,35)$ & $++(29,35,38)$ & $0(29,35,38,39)$ & $+(40,41)$ & $+(31,32)$ & $++(35)$ \\
\hline $\begin{array}{l}\text { Lasofoxifene } \\
\text { (SERM Gen 3) }\end{array}$ & $-(35,42)$ & $+++(43,44)$ & $++(35,42,45)$ & UN & UN & $++^{\star}(35,42,46)$ \\
\hline
\end{tabular}

-, antagonistic effect; 0, neutral effect; +, mild agonistic effect; ++, moderate agonistic effect; +++, major agonistic effects; UN, unclear/unknown; MR, mixed results.

*Literature indicates increased DVT risk but lowered risk of heart disease and stroke associated with lasofoxifene (26, 47). 
skin. Though these changes may assist in the partial feminization of a non-binary individual AMAB, the effects of SERMs on skin and body composition are not widely studied outside of the population of post-menopausal cisgender women and further research is needed.

\section{SERMs Can Inhibit Breast Tissue Growth}

Most SERMs inhibit the effects of estradiol on breast tissue growth and consequently are used to treat estradiol-responsive breast cancers $(23,49)$. Historically, tamoxifen has been the most commonly utilized SERM for treatment of metastatic, estrogen receptor-positive $(\mathrm{ER}+)$ cancers, where it is effective in lowering recurrence and mortality rates (23). Though not as commonly used for breast cancer treatment, newer SERMs such as RLX are also anti-estrogenic in breast tissue and deter breast cancer growth (35).

Consistent with their anti-estrogenic effect on breast tissue, SERMs such as tamoxifen have been reported as an effective alternative to surgery to treat persistent gynaecomastia in cisgender adolescent and adult males $(49,50)$. They have also been shown to improve symptoms associated with juvenile breast hypertrophy in adolescent cisgender females $(51,52)$. Although these studies involved small numbers of patients, they suggest that SERMs could help avoid breast growth in non-binary people $\mathrm{AMAB}$ who desire some feminization without breast development.

\section{SERMs and Bone Health}

While promoting partial feminization without breast growth, SERMs have pro-estrogenic effects on bones and could also theoretically mitigate negative bone effects associated with GnRHa and/or anti-androgen use in non-binary adolescents and adults AMAB. A variety of SERMs have now been approved for treating osteoporosis in adults $(23,43)$ based upon their ability to improve BMD and/or fracture risk by up to $55 \%$ (39) in postmenopausal cisgender women. However, whether this occurs in people $A M A B$ who may also be androgen deficient is unknown.

Though tamoxifen, RLX and lasofoxifene have all been associated with increases in BMD in post-menopausal cisgender women, there may be important differences between different generation SERMs in terms of bone health. For instance, only RLX and lasofoxifene have shown fracture benefit. Moreover, while lasofoxifene reduces the incidence of both vertebral and non-vertebral fractures (45), RLX was found to reduce the incidence of vertebral but not non-vertebral fractures $(38,39)$. It should also be noted that the reduction of fracture risk (particularly at the hip) for SERMs is less than that of bisphosphonates. As such, SERMs are frequently reserved for use in osteoporosis under specific scenarios (i.e. for younger post-menopausal cisgender women or those with a family history of invasive breast cancer) (43).

Importantly, the positive bone health effects of SERMs in postmenopausal cisgender women cannot be directly extrapolated to gender non-binary young people AMAB. Post-menopausal cisgender women have already attained peak bone mass (PBM) in early adulthood (53), and it is the physiological estradiol deficiency that causes post-menopausal declines in BMD (54).
In contrast, adolescence is associated with a significant increase in BMD directly resulting from effects of pubertal hormones. Adolescents exhibit an average annual accrual of 6-10\% and an overall doubling from childhood through the mid 20s (55). Hence, use of SERMs to potentially promote bone health in trans adolescents AMAB would be physiologically distinct from their use in post-menopausal cisgender women. Specifically, while the latter seeks to maintain BMD that has already peaked and has strong supporting evidence, the former aims to promote the attainment of PBM which is a context in which SERMs are untested. Thus, it is unclear to what extent - if at all - SERMs increase BMD during adolescence and how PBM would be affected.

Indeed, there is evidence that questions the extent of SERMs' pro-estrogenic effects on bones. For example, in a three-year prospective study of premenopausal cisgender women treated with tamoxifen for breast cancer, the average annual lumbar spine BMD fell $1.4 \%$, compared to a $0.2 \%$ increase in those who received a placebo. These results prompted the authors to conclude that tamoxifen can act as a partial competitive antagonist of endogenous estradiol to cause increased bone remodelling (56). Similarly, another study on postchemotherapy tamoxifen usage in cisgender women with breast cancer found that premenopausal patients experienced a $4.6 \%$ decrease in their baseline BMD compared to a $0.6 \%$ gain in $\mathrm{BMD}$ in those not on tamoxifen. However, it should be noted that this result may have been confounded by the fact that those who received tamoxifen were from the outset inherently different to those who did not (based on hormone receptor status of their tumors) (57). While both of these studies focused on tamoxifen use in adults with breast cancer, if similar findings held true in healthy adolescents with SERMs, the use of SERMs might in fact be detrimental to the bone health of trans young people.

Hence, caution is required. With no studies having assessed bone outcomes in trans people using SERMs, further research is required, including in those $\mathrm{AMAB}$. Thus far, pre-clinical data has shown that lasofoxifene prevented bone loss by inhibiting bone turnover related to aging and low serum testosterone levels in male rats (58). In addition, a study of cisgender men with prostate cancer found that RLX prevented harmful effects of GnRHa on bone, including bone loss (59). While the use of SERMs in this context might arguably be the most directly analogous to their potential use in trans people AMAB, clearly further assessment of the skeletal effects of SERMs in adolescents and adults $\mathrm{AMAB}$ are required.

\section{Effects of SERMs on Other Body Systems}

Given that significant brain maturation occurs during adolescence, testosterone and estradiol may potentially facilitate adolescent brain development and functioning. It is unknown whether the absence of sex steroids secondary to GnRHa use in trans adolescents has any cognitive effects (17). Similarly, the effects of SERMs on brain development and function are uncertain. In vitro studies have suggested that SERMs promote synaptic transmission, increase axonal growth, and facilitate the regeneration of damaged synapses $(60,61)$. In vivo use of tamoxifen in animal models and cisgender women with breast cancer is associated with improved cognitive function $(62,63)$. 
The relevance of such findings for the use of SERMs in nonbinary individuals AMAB is unclear.

Among cisgender males, lower sex hormone concentrations in adulthood have also been associated with an increased risk of cardiovascular disease $(64,65)$. Interestingly, a recent study of >8000 60-80 year-old post-menopausal cisgender women receiving daily lasofoxifene showed a $32 \%$ reduction in major coronary events over five years compared to hypogonadal postmenopausal cisgender women (45). While these findings suggest that SERMs might promote cardiovascular health, such effects again cannot be directly extrapolated to non-binary people $A M A B$, given likely different mechanisms underlying their cardiovascular risk profile.

\section{Health Risks of SERMs}

Common side effects of SERMs include hair loss, nausea, mood disturbance, and hot flashes $(23,43)$. In addition, long-term use of SERMs have been associated with several other risks, all of which are important to consider when balancing their potential use as a gender affirming treatment.

First, as previously observed with estrogen replacement therapy for postmenopausal cisgender women (34), an increased risk of thromboembolic events has been associated with SERM use. RLX has been shown to increase the risk of deep vein thrombosis by up to $54 \%$ and the risk of pulmonary embolism by $91 \%$ (66). Similar data is available for tamoxifen (37). Whether the rates of stroke and myocardial infarctions are also increased remains unclear, with previous studies showing inconsistent results $(29,67,68)$.

Secondly, long-term SERM use has been associated with hypertriglyceridemia and hepatic steatosis (69), as well as altered glucose metabolism and increased risk of diabetes (70). In a 12year longitudinal study involving over 22,000 cisgender women with breast cancer, a $31 \%$ increased diabetes risk was observed in tamoxifen users versus non-users (71). Notably, the majority of SERM-based metabolic studies have been conducted on cisgender women with and without breast cancer (69). Whether similar metabolic effects would occur in those $A M A B$ is unclear.

Finally, SERM use can increase testosterone production in those AMAB, owing to their antagonistic actions at the estrogen receptor within the hypothalamus and pituitary. Specifically, tamoxifen was found to increase serum FSH, LH and testosterone levels in cisgender men by less than 2-fold, while raloxifene showed only minimal increase (47). The clinical relevance of such changes is unclear but, may cause or further exacerbate unwanted masculinization.

\section{CLINICAL IMPLICATIONS}

Whilst SERMs should not be routinely recommended as treatment options, clinicians may encounter scenarios where SERMs may be requested by patients AMAB who desire feminization of skin or fat distribution without breast growth. Indeed, we are aware of SERMs already being used anecdotally by adults in this context. For patients wanting to use SERMs to affirm their gender, the lack of evidence for efficacy or safety must be highlighted, and there should be a clear explanation that treatment is experimental. To provide informed consent, individuals need to understand the selective differential effects of SERMs, their potential lack of benefit, and the risk of adverse effects. If a shared decision between patient and doctor is made to trial the use of a SERM, then clear goals of treatment (e.g., fat redistribution) over a pre-specified timeline (e.g., 3-6 months) should be determined. If treatment goals are not achieved, treatment should be ceased. Given Raloxifene is the only SERM with evidence for agonistic effects on fat and body composition $(40,41)$, it would appear to be the most suitable choice at present and would ideally be used in the context of a prospective research study. Consistent with this, clinical trials ideally across multiple centers to aid in patient recruitment - are required to provide greater evidence regarding the potential benefits and harms of using SERMs in non-binary individuals.

\section{CONCLUSION}

In the clinical setting, increasing numbers of non-binary individuals are seeking gender-affirming hormone therapy, and some desire androgynous physical characteristics to align with their gender identity. This can pose challenges in tailoring treatment options, and a lack of well-defined therapeutic pathways leaves non-binary people at risk of persistent GD and ongoing vulnerability to adverse mental health outcomes. SERMs may be a theoretically attractive option for non-binary people $A M A B$ who desire partial feminization without breast growth. However, there is a dearth of evidence regarding the safety and efficacy of SERMs in this context. An individualised, shared decision-making approach to care is therefore needed when considering the use of SERMs in non-binary people, with acknowledgement of their experimental nature, significant potential risk and need for further research.

\section{DATA AVAILABILITY STATEMENT}

The original contributions presented in the study are included in the article/supplementary material. Further inquiries can be directed to the corresponding author.

\section{AUTHOR CONTRIBUTIONS}

JX performed the relevant literature review, screened studies for inclusion, extracted relevant information from the included articles, drafted the initial manuscript, and revised the manuscript. KP conceptualised the manuscript and, together with $\mathrm{LN}, \mathrm{AC}, \mathrm{MO}$ 'C, and $\mathrm{SZ}$ reviewed and revised the manuscript. All authors contributed to the article and approved the submitted version. 


\section{FUNDING}

KP is supported by fellowships from the Royal Children's Hospital Foundation and Hugh Williamson Trust Foundation. AC is supported by an Australian Government National Health and Medical Research Council Early Career Fellowship (\#1143333)

\section{REFERENCES}

1. Cheung AS, Leemaqz SY, Wong JWP, Chew D, Ooi O, Cundill P, et al. NonBinary and Binary Gender Identity in Australian Trans and Gender Diverse Individuals. Arch Sex Behav (2020) 49(7):2673-81. doi: 10.1007/s10508-02001689-9

2. Chew D, Tollit MA, Poulakis Z, Zwickl S, Cheung AS, Pang KC. Youths With a non-Binary Gender Identity: A Review of Their Sociodemographic and Clinical Profile. Lancet Child Adolesc Health (2020) 4(4):322-30. doi: 10.1016/ S2352-4642(19)30403-1

3. Zwickl S, Wong A, Bretherton I, Rainier M, Chetcuti D, Zajac JD, et al. Health Needs of Trans and Gender Diverse Adults in Australia: A Qualitative Analysis of a National Community Survey. Int J Environ Res Public Health (2019) 16(24):5088. doi: 10.3390/ijerph16245088

4. Aparicio-Garcia ME, Diaz-Ramiro EM, Rubio-Valdehita S, Lopez-Nunez MI, Garcia-Nieto I. Health and Well-Being of Cisgender, Transgender and NonBinary Young People. Int J Environ Res Public Health (2018) 15(10):2133. doi: $10.3390 /$ ijerph 15102133

5. Clark BA, Veale JF, Townsend M, Frohard-Dourlent H, Saewyc E. NonBinary Youth: Access to Gender-Affirming Primary Health Care. Int $J$ Transgend (2018) 19(2):158-69. doi: 10.1080/15532739.2017.1394954

6. Lykens JE, LeBlanc AJ, Bockting WO. Healthcare Experiences Among Young Adults Who Identify as Genderqueer or Nonbinary. LGBT Health (2018) 5 (3):191-6. doi: 10.1089/lgbt.2017.0215

7. Dhejne C, Van Vlerken R, Heylens G, Arcelus J. Mental Health and Gender Dysphoria: A Review of the Literature. Int Rev Psychiatry (2016) 28(1):44-57. doi: 10.3109/09540261.2015.1115753

8. Thorne N, Witcomb GL, Nieder T, Nixon E, Yip A, Arcelus J. A Comparison of Mental Health Symptomatology and Levels of Social Support in Young Treatment Seeking Transgender Individuals Who Identify as Binary and Non-Binary. Int J Transgend (2019) 20(2-3):241-50. doi: 10.1080/15532739. 2018.1452660

9. Twist J, de Graaf NM. Gender Diversity and non-Binary Presentations in Young People Attending the United Kingdom's National Gender Identity Development Service. Clin Child Psychol Psychiatry (2019) 24(2):277-90. doi: 10.1177/1359104518804311

10. World Professional Association for Transgender Health. Standards of Care for the Health of Transsexual, Transgender, and Gender-Conforming People [7th Version]. (2012). Available at: https://www.wpath.org/publications/soc.

11. UCSF Transgender Care, Department of Family and Community Medicine, University of California San Francisco. Guidelines for the Primary and Gender-Affirming Care of Transgender and Gender Nonbinary People; 2nd edition. Deutsch MB, ed. (2016). Available at transcare.ucsf.edu/guidelines.

12. Cocchetti C, Ristori J, Romani A, Maggi M, Fisher AD. Hormonal Treatment Strategies Tailored to Non-Binary Transgender Individuals. J Clin Med (2020) 9(6):1609. doi: 10.3390/jcm9061609

13. Telfer MM, Tollit MA, Pace CC, Pang KC. Australian Standards of Care and Treatment Guidelines for Transgender and Gender Diverse Children and Adolescents. Med J Aust (2018) 209(3):132-6. doi: 10.5694/mja17.01044

14. Hembree WC, Cohen-Kettenis PT, Gooren L, Hannema SE, Meyer WJ, Murad MH, et al. Endocrine Treatment of Gender-Dysphoric/GenderIncongruent Persons: An Endocrine Society Clinical Practice Guideline. J Clin Endocrinol Metab (2017) 102(11):3869-903. doi: 10.1210/jc.2017-01658

15. Pang KC, Notini L, McDougall R, Gillam L, Savulescu J, Wilkinson D, et al. Long-Term Puberty Suppression for a Nonbinary Teenager. Pediatrics (2020) 145(2):e20191606. doi: 10.1542/peds.2019-1606

16. Giovanardi G. Buying Time or Arresting Development? The Dilemma of Administering Hormone Blockers in Trans Children and Adolescents. Porto BioMed J (2017) 2(5):153-6. doi: 10.1016/j.pbj.2017.06.001 and receives support from the Viertel Charitable Foundation Clinical Investigator Award, Endocrine Society of Australia KenWynne Award and Royal Australasian College of Physicians Foundation. MO'C, LN, and KP acknowledge the infrastructure funding received from the Victorian State Government through the Operational Infrastructure Support (OIS) Program.

17. Chew D, Anderson J, Williams K, May T, Pang K. Hormonal Treatment in Young People With Gender Dysphoria: A Systematic Review. Pediatrics (2018) 141(4):e20173742. doi: 10.1542/peds.2017-3742

18. Stagi S, Cavalli L, Iurato C, Seminara S, Brandi ML, de Martino M. Bone Metabolism in Children and Adolescents: Main Characteristics of the Determinants of Peak Bone Mass. Clin Cases Miner Bone Metab (2013) 10 (3):172-9.

19. Ferguson G, Simm P, O'Connell M, Pang KC. Gender Dysphoria: Puberty Blockers and Loss of Bone Mineral Density. BMJ (2019) 367:16471. doi: 10.1136/bmj.16471

20. Vlot MC, Klink DT, den Heijer M, Blankenstein MA, Rotteveel J, Heijboer AC. Effect of Pubertal Suppression and Cross-Sex Hormone Therapy on Bone Turnover Markers and Bone Mineral Apparent Density (BMAD) in Transgender Adolescents. Bone (2017) 95:11-9. doi: 10.1016/j.bone.2016.11.008

21. Mahfouda S, Moore JK, Siafarikas A, Zepf FD, Lin A. Puberty Suppression in Transgender Children and Adolescents. Lancet Diabetes Endocrinol (2017) 5 (10):816-26. doi: 10.1016/S2213-8587(17)30099-2

22. Sadjadi S. The Endocrinologist's Office-Puberty Suppression: Saving Children From a Natural Disaster? J Med Humanit (2013) 34(2):255-60. doi: 10.1007/ s10912-013-9228-6

23. Mirkin S, Pickar JH. Selective Estrogen Receptor Modulators (SERMs): A Review of Clinical Data. Maturitas (2015) 80(1):52-7. doi: 10.1016/ j.maturitas.2014.10.010

24. Notini L, Earp BD, Gillam L, McDougall RJ, Savulescu J, Telfer M, et al. Forever Young? The Ethics of Ongoing Puberty Suppression for Non-Binary Adults. J Med Ethics (2020) 46(11):743-52. doi: 10.1136/medethics-2019106012

25. Notini L, Pang KC, Telfer M, McDougall R. "No One Stays Just on Blockers Forever": Clinicians' Divergent Views and Practices Regarding Puberty Suppression for Nonbinary Young People. J Adolesc Health (2020) 68 (6):1189-96. doi: 10.1016/j.jadohealth.2020.09.028

26. Park HK, Lee HS, Ko JH, Hwang IT, Lim JS, Hwang JS. The Effect of Gonadotrophin-Releasing Hormone Agonist Treatment Over 3 Years on Bone Mineral Density and Body Composition in Girls With Central Precocious Puberty. Clin Endocrinol (Oxf) (2012) 77(5):743-8. doi: 10.1111/ j.1365-2265.2012.04418.x

27. Guo Z, Huang Y, Gong L, Gan S, Chan FL, Gu C, et al. Association of Androgen Deprivation Therapy With Thromboembolic Events in Patients With Prostate Cancer: A Systematic Review and Meta-Analysis. Prostate Cancer Prostatic Dis (2018) 21(4):451-60. doi: 10.1038/s41391-018-0059-4

28. Hariri L, Rehman A. Estradiol. In: Statpearls. Treasure Island (FL): StatPearls Publishing (2021). Available at: https://www.ncbi.nlm.nih.gov/books/ NBK549797/.

29. Maximov PY, Lee TM, Jordan VC. The Discovery and Development of Selective Estrogen Receptor Modulators (SERMs) for Clinical Practice. Curr Clin Pharmacol (2013) 8(2):135-55. doi: 10.2174/1574884711308020006

30. Pedersen SB, Kristensen K, Hermann PA, Katzenellenbogen JA, Richelsen B. Estrogen Controls Lipolysis by Up-Regulating alpha2A-adrenergic Receptors Directly in Human Adipose Tissue Through the Estrogen Receptor Alpha. Implications for the Female Fat Distribution. J Clin Endocrinol Metab (2004) 89(4):1869-78. doi: 10.1210/jc.2003-031327

31. Sumino H, Ichikawa S, Kasama S, Takahashi T, Kumakura H, Takayama Y, et al. Effects of Raloxifene and Hormone Replacement Therapy on Forearm Skin Elasticity in Postmenopausal Women. Maturitas (2009) 62(1):53-7. doi: 10.1016/j.maturitas.2008.10.005

32. Surazynski A, Jarzabek K, Haczynski J, Laudanski P, Palka J, Wolczynski S. Differential Effects of Estradiol and Raloxifene on Collagen Biosynthesis in Cultured Human Skin Fibroblasts. Int J Mol Med (2003) 12(5):803-9. doi: 10.3892/ijmm.12.5.803 
33. Stevenson S, Thornton J. Effect of Estrogens on Skin Aging and the Potential Role of SERMs. Clin Interv Aging (2007) 2(3):283-97. doi: 10.2147/CIA.S798

34. Gomes MP, Deitcher SR. Risk of Venous Thromboembolic Disease Associated With Hormonal Contraceptives and Hormone Replacement Therapy: A Clinical Review. Arch Intern Med (2004) 164(18):1965-76. doi: 10.1001/ archinte.164.18.1965

35. Hadji P. The Evolution of Selective Estrogen Receptor Modulators in Osteoporosis Therapy. Climacteric (2012) 15(6):513-23. doi: 10.3109/ 13697137.2012.688079

36. Cooke AL, Metge C, Lix L, Prior HJ, Leslie WD. Tamoxifen Use and Osteoporotic Fracture Risk: A Population-Based Analysis. J Clin Oncol (2008) 26(32):5227-32. doi: 10.1200/JCO.2007.15.7123

37. Hernandez RK, Sorensen HT, Pedersen L, Jacobsen J, Lash TL. Tamoxifen Treatment and Risk of Deep Venous Thrombosis and Pulmonary Embolism: A Danish Population-Based Cohort Study. Cancer (2009) 115(19):4442-9. doi: $10.1002 /$ cncr.24508

38. Delmas PD, Ensrud KE, Adachi JD, Harper KD, Sarkar S, Gennari C, et al. Efficacy of Raloxifene on Vertebral Fracture Risk Reduction in Postmenopausal Women With Osteoporosis: Four-Year Results From a Randomized Clinical Trial. J Clin Endocrinol Metab (2002) 87(8):3609-17. doi: $10.1210 /$ jcem. 87.8 .8750

39. Ettinger B, Black DM, Mitlak BH, Knickerbocker RK, Nickelsen T, Genant HK, et al. Reduction of Vertebral Fracture Risk in Postmenopausal Women With Osteoporosis Treated With Raloxifene: Results From a 3-Year Randomized Clinical Trial. Multiple Outcomes of Raloxifene Evaluation (More) Investigators. JAMA (1999) 282(7):637-45. doi: 10.1001/ jama.282.7.637

40. Francucci CM, Daniele P, Iori N, Camilletti A, Massi F, Boscaro M. Effects of Raloxifene on Body Fat Distribution and Lipid Profile in Healthy PostMenopausal Women. J Endocrinol Invest (2005) 28(7):623-31. doi: 10.1007/ BF03347261

41. Jacobsen DE, Samson MM, Emmelot-Vonk MH, Verhaar HJ. Raloxifene and Body Composition and Muscle Strength in Postmenopausal Women: A Randomized, Double-Blind, Placebo-Controlled Trial. Eur J Endocrinol (2010) 162(2):371-6. doi: 10.1530/EJE-09-0619

42. Cummings SR, Ensrud K, Delmas PD, LaCroix AZ, Vukicevic S, Reid DM, et al. Lasofoxifene in Postmenopausal Women With Osteoporosis. N Engl J Med (2010) 362(8):686-96. doi: 10.1056/NEJMoa0808692

43. An KC. Selective Estrogen Receptor Modulators. Asian Spine J (2016) 10 (4):787-91. doi: 10.4184/asj.2016.10.4.787

44. McClung MR, Siris E, Cummings S, Bolognese M, Ettinger M, Moffett A, et al. Prevention of Bone Loss in Postmenopausal Women Treated With Lasofoxifene Compared With Raloxifene. Menopause (2006) 13(3):377-86. doi: 10.1097/01.gme.0000188736.69617.4f

45. Gennari L, Merlotti D, Nuti R. Selective Estrogen Receptor Modulator (SERM) for the Treatment of Osteoporosis in Postmenopausal Women: Focus on Lasofoxifene. Clin Interv Aging (2010) 5:19-29. doi: 10.2147/ CIA.S6083

46. Ensrud K, LaCroix A, Thompson JR, Thompson DD, Eastell R, Reid DM, et al. Lasofoxifene and Cardiovascular Events in Postmenopausal Women With Osteoporosis: Five-year Results From the Postmenopausal Evaluation and Risk Reduction With Lasofoxifene (PEARL) Trial. Circulation (2010) 122 (17):1716-24. doi: 10.1161/CIRCULATIONAHA.109.924571

47. Tsourdi E, Kourtis A, Farmakiotis D, Katsikis I, Salmas M, Panidis D. The Effect of Selective Estrogen Receptor Modulator Administration on the Hypothalamic-Pituitary-Testicular Axis in Men With Idiopathic Oligozoospermia. Fertil Steril (2009) 91(4 Suppl):1427-30. doi: 10.1016/ j.fertnstert.2008.06.002

48. Sermonix Receives Fda Fast Track Designation for Investigational Drug Lasofoxifene (2019).

49. Zehetner A. Tamoxifen to Treat Male Pubertal Gynaecomastia. Int J Pediatr Adolesc Med (2015) 2(3-4):152-6. doi: 10.1016/j.ijpam.2015.09.002

50. Khan HN, Rampaul R, Blamey RW. Management of Physiological Gynaecomastia With Tamoxifen. Breast (2004) 13(1):61-5. doi: 10.1016/ j.breast.2003.10.005

51. O’Hare PM, Frieden IJ. Virginal Breast Hypertrophy. Pediatr Dermatol (2000) 17(4):277-81. doi: 10.1046/j.1525-1470.2000.01774.x
52. Demir K, Unuvar T, Eren S, Abaci A, Bober E. Tamoxifen as First-Line Treatment in a Premenarchal Girl With Juvenile Breast Hypertrophy. J Pediatr Adolesc Gynecol (2010) 23(5):e133-6. doi: 10.1016/j.jpag.2009. 11.003

53. Berger C, Goltzman D, Langsetmo L, Joseph L, Jackson S, Kreiger N, et al. Peak Bone Mass From Longitudinal Data: Implications for the Prevalence, Pathophysiology, and Diagnosis of Osteoporosis. J Bone Miner Res (2010) 25 (9):1948-57. doi: 10.1002/jbmr.95

54. Sverrisdottir A, Fornander T, Jacobsson H, von Schoultz E, Rutqvist LE. Bone Mineral Density Among Premenopausal Women With Early Breast Cancer in a Randomized Trial of Adjuvant Endocrine Therapy. J Clin Oncol (2004) 22 (18):3694-9. doi: 10.1200/JCO.2004.08.148

55. McCormack SE, Cousminer DL, Chesi A, Mitchell JA, Roy SM, Kalkwarf HJ, et al. Association Between Linear Growth and Bone Accrual in a Diverse Cohort of Children and Adolescents. JAMA Pediatr (2017) 171(9):e171769. doi: 10.1001/jamapediatrics.2017.1769

56. Powles TJ, Hickish T, Kanis JA, Tidy A, Ashley S. Effect of Tamoxifen on Bone Mineral Density Measured by Dual-Energy X-Ray Absorptiometry in Healthy Premenopausal and Postmenopausal Women. J Clin Oncol (1996) 14(1):7884. doi: 10.1200/JCO.1996.14.1.78

57. Vehmanen L, Elomaa I, Blomqvist C, Saarto T. Tamoxifen Treatment After Adjuvant Chemotherapy Has Opposite Effects on Bone Mineral Density in Premenopausal Patients Depending on Menstrual Status. J Clin Oncol (2006) 24(4):675-80. doi: 10.1200/JCO.2005.02.3515

58. Ke HZ, Qi H, Crawford DT, Chidsey-Frink KL, Simmons HA, Thompson DD. Lasofoxifene (CP-336,156), A Selective Estrogen Receptor Modulator, Prevents Bone Loss Induced by Aging and Orchidectomy in the Adult Rat. Endocrinology (2000) 141(4):1338-44. doi: 10.1210/endo.141.4.7408

59. Smith MR, Fallon MA, Lee H, Finkelstein JS. Raloxifene to Prevent Gonadotropin-Releasing Hormone Agonist-Induced Bone Loss in Men With Prostate Cancer: A Randomized Controlled Trial. J Clin Endocrinol Metab (2004) 89(8):3841-6. doi: 10.1210/jc.2003-032058

60. Arevalo MA, Santos-Galindo M, Lagunas N, Azcoitia I, Garcia-Segura LM. Selective Estrogen Receptor Modulators as Brain Therapeutic Agents. J Mol Endocrinol (2011) 46(1):R1-9. doi: 10.1677/JME-10-0122

61. Crider A, Pillai A. Estrogen Signaling as a Therapeutic Target in Neurodevelopmental Disorders. J Pharmacol Exp Ther (2017) 360(1):48-58. doi: 10.1124/jpet.116.237412

62. Sun LM, Chen HJ, Liang JA, Kao CH. Long-Term Use of Tamoxifen Reduces the Risk of Dementia: A Nationwide Population-Based Cohort Study. QJM (2016) 109(2):103-9. doi: 10.1093/qjmed/hcv072

63. Zabihi H, Hosseini M, Pourganji M, Oryan S, Soukhtanloo M, Niazmand S. The Effects of Tamoxifen on Learning, Memory and Brain Tissues Oxidative Damage in Ovariectomized and Naive Female Rats. Adv BioMed Res (2014) 3:219. doi: $10.4103 / 2277-9175.143297$

64. Potenza M, Shimshi M. Male Hypogonadism: The Unrecognized Cardiovascular Risk Factor. J Clin Lipidol (2008) 2(2):71-8. doi: 10.1016/ j.jacl.2008.01.011

65. Laughlin GA, Barrett-Connor E, Bergstrom J. Low Serum Testosterone and Mortality in Older Men. J Clin Endocrinol Metab (2008) 93(1):68-75. doi: 10.1210/jc.2007-1792

66. Adomaityte J, Farooq M, Qayyum R. Effect of Raloxifene Therapy on Venous Thromboembolism in Postmenopausal Women. A Meta-Analysis. Thromb Haemost (2008) 99(2):338-42. doi: 10.1160/TH07-07-0468

67. Muchmore DB. Raloxifene: A Selective Estrogen Receptor Modulator (SERM) With Multiple Target System Effects. Oncologist (2000) 5(5):388-92. doi: 10.1634/theoncologist.5-5-388

68. Sexton MJ, Gherman RB. Selective Estrogen Receptor Modulators: The Ideal Estrogen Replacement?(2)(2). Prim Care Update Ob Gyns (2001) 8(1):25-30 doi: 10.1016/S1068-607X(00)00066-4

69. Xu B, Lovre D, Mauvais-Jarvis F. Effect of Selective Estrogen Receptor Modulators on Metabolic Homeostasis. Biochimie (2016) 124:92-7. doi: 10.1016/j.biochi.2015.06.018

70. Le May C, Chu K, Hu M, Ortega CS, Simpson ER, Korach KS, et al. Estrogens Protect Pancreatic Beta-Cells From Apoptosis and Prevent Insulin-Deficient Diabetes Mellitus in Mice. Proc Natl Acad Sci USA (2006) 103(24):9232-7. doi: $10.1073 /$ pnas. 0602956103 
71. Sun LM, Chen HJ, Liang JA, Li TC, Kao CH. Association of Tamoxifen Use and Increased Diabetes Among Asian Women Diagnosed With Breast Cancer. Br J Cancer (2014) 111(9):1836-42. doi: 10.1038/bjc.2014.488

Conflict of Interest: The authors declare that the research was conducted in the absence of any commercial or financial relationships that could be construed as a potential conflict of interest.
Copyright (®) $2021 \mathrm{Xu}$, O'Connell, Notini, Cheung, Zwickl and Pang. This is an openaccess article distributed under the terms of the Creative Commons Attribution License (CC BY). The use, distribution or reproduction in other forums is permitted, provided the original author(s) and the copyright owner(s) are credited and that the original publication in this journal is cited, in accordance with accepted academic practice. No use, distribution or reproduction is permitted which does not comply with these terms. 